\title{
BMJ Open Improving the primary-secondary care interface in Scotland: a qualitative exploration of impact on clinicians of an educational complex intervention
}

To cite: Sampson $R$, MacVicar R, Wilson P. Improving the primary-secondary care interface in Scotland: a qualitative exploration of impact on clinicians of an educational complex intervention. BMJ Open 2017;7:e016593. doi:10.1136/ bmjopen-2017-016593

- Prepublication history for this paper is available online. To view these files please visit the journal online (http://dx.doi. org/10.1136/bmjopen-2017016593)

Received 24 February 2017 Revised 12 May 2017 Accepted 26 May 2017

CrossMark

${ }^{1}$ General Practitioner, Cairn Medical Practice, Inverness, Scotland

${ }^{2}$ Postgraduate Dean, NHS Education for Scotland, North of Scotland Region, Scotland

${ }^{3}$ Professor of Primary Care and Rural Health, The Centre for Health Science, University of Aberdeen, Inverness, Scotland

Correspondence to

Dr Rod Sampson; rod.

sampson@nhs.net

\section{ABSTRACT}

Objectives To determine the impact on clinicians and any consequent influence on patient care of taking part in the bespoke interface-focused educational intervention.

Design Qualitative design.

Setting Primary and secondary care centres in NHS Highland health board area, Scotland.

Participants 33 urban-based clinicians (18 general practitioners and 15 hospital specialists) in NHS Highland, Scotland.

Intervention An interface-focused educational intervention was carried out in primary and secondary care centres in NHS Highland health board area, Scotland. Eligible clinicians were invited to take part in the intervention which involved facilitated small group work, and use of a bespoke educational module. Subsequent one-to-one interviews explored the impact of the intervention. A standard thematic analysis was used, comprising an iterative process based on grounded theory. Results Key themes that emerged included fresh insights (in relation to those individuals and processes across the interface), adoption of new behaviours (eg, being more empowered to directly contact a colleague, taking steps to reduce the others workload and changes in professional approach) and changes in terms of communication (including a desire to communicate more effectively, with use of different modes and methods).

Conclusion The study highlighted key areas that may serve as useful outcomes for a large-scale randomised trial. Addressing issues identified in the study may help to improve interface relationships and benefit patient care.

\section{INTRODUCTION}

In those countries with 'gatekeeping' primary care systems, an increased research focus on the interface between primary and secondary care has highlighted the importance of improving working relationships across the interface, for the benefit of patient care. ${ }^{1}$ In the midst of tensions at this interface, clinicians see education as a tool for developing such relationships, with a desire to emphasise a model of shared learning. ${ }^{2}$

Interprofessional education (IPE) occurs when members of more than one healthcare

\section{Strengths and limitations of this study}

- No data were collected on those clinicians who chose not to respond to study invitations, or who initially agreed to take part and then withdrew. Therefore, it is not known whether potential differences between participants and non-participants were important.

- Having a balance of co-facilitators (one from each of primary and secondary care) was an asset, helping to minimise any sense of bias in terms of group dynamics for participants.

- Compared with 'standard' educational small groups (where relationships are built over time), these oneoff sessions consisted of people who may have met for the first time. This may have hindered willingness to be 'open'.

- Module content encouraged group working since case scenario topics were relevant to the participants.

- The principal investigator (RS) is a general practitioner in the area where the study took place, which may have influenced participant responses (both in terms of recruitment and what people actually said).

profession learn interactively together, with the explicit purpose of improving collaboration and/or the health/well-being of patients. ${ }^{3}$ Reeves et al called for IPE that breaks down established silos, with IPE seen as fundamental to clinical practice improvement. $^{3}$

Our previous work has used qualitative synthesis ${ }^{4}$ along with primary qualitative research $^{2} 5$ to provide the foundation for the creation of an interface-focused IPE intervention $^{6}$ aiming to develop collaborative relationships for the benefit of patient care. The intervention is an interface-focused PBSGL (Practice-Based Small Group Learning) module, a resource for small group work involving facilitated discussion around case scenarios with a focus on reflection on practice, strategies to enhance change in 
practice and commitment to practice change, all with the aim of improving patient care. ${ }^{7}$ The development of the intervention was aligned with the Medical Research Council framework for complex intervention development and evaluation. ${ }^{8}$

While studies exist looking at IPE within healthcare, ${ }^{3}$ we are not aware of any research exploring the two 'tribes' (of general practitioners (GPs) and hospital specialists) sitting down together to learn from one another. Also, few qualitative research projects make efforts to determine or achieve impact, with researchers placing relatively low emphasis on the processes and interactions through which indirect impacts occur. ${ }^{9}$

Our present study set out to explore the impact on clinicians and any consequent influence on patient care of taking part in the bespoke interface-focused educational intervention. Identified impact may generate measurable outcomes for a randomised trial of the intervention: it is desirable that such groundwork should be done prior to 'racing ahead.'10 11

\section{METHOD}

The context for this work is in NHS Scotland, where GPs act as 'gatekeepers' to secondary care. The study was conducted between May and September 2016 in NHS Highland (geographically, the largest Scottish Health Board, covering an area of $32500 \mathrm{~km}^{2}$ and serving a population of 320000 people). ${ }^{12}$

Clinicians were purposively sampled, and those meeting eligibility criteria (see online supplementary appendix 1) were sent an electronic study invitation (see online supplementary appendix 2) along with a participant information sheet (see online supplementary appendix $3)$. Those not responding to invitation were subsequently sent a further invitation 2 weeks later. Those failing to respond to both invitations were excluded.

Using Microsoft Excel's random number generator (and influenced by individual participants' date preferences expressed via a 'hidden' Doodle poll), clinicians who agreed to take part were allocated to one of three distinct small groups. A 'hidden' poll was chosen to ensure clinicians that expressed their availability were not influenced by knowledge of other participants that were taking part. Groups consisted of equal numbers of primary and secondary care clinicians, with a maximum total number of 12 .

Consent was obtained from participants using a standard form on arrival at the group, and then asked to complete a presession questionnaire to determine reasons and aspirations for taking part (see online supplementary appendix 4). Participants were encouraged to sit next to colleagues from the other side of the interface, to ensure that primary or secondary care clinicians were not grouped together in the circle-seating plan. Small-group facilitators (from both primary and secondary care, each having received training in PBSGL methodology) 'led' the small group through the session using the bespoke
PBSGL module. Areas explored reflected module content, with case scenarios for discussion covering topics including communication, work transfer, education, relationships and the role of the wider clinical team. The session was audio-recorded, and RS observed the group, taking field notes.

Immediately following the session, participants were asked to complete a postsession questionnaire (see online supplementary appendix 4) which explored their experience of the session, and served as a useful prompt to document any 'commitment to change' statements, an inherent part of the PBSGL process.

Approximately 3 months postparticipation, each of the participants took part in a one-to-one telephone interview with RS, which was audio-recorded. A semistructured interview schedule (see online supplementary appendix 5) was developed and adopted by the research team to allow a more open exploration of experience and impact. A summary of participant activity is seen in figure 1 .

Presession and postsession questionnaire responses, transcriptions of the group work and subsequent one-to-one interviews were entered into nVivo V.11.1.

Analysis of the data broadly used a grounded theory approach, with initial coding generating ideas inductively from the data. Constant comparison of codes and data helped develop emergent themes, which the research team discussed and contextualised when meeting regularly. All 33 participant responses were analysed, with a sense of data saturation after approximately 24 interviews. ${ }^{13}$

\section{RESULTS}

A total of 33 participants took part in the intervention. Figure 2 shows the invitation, response rate and subsequent involvement of study participants.

Similar numbers of male and female clinicians took part, and among participating hospital consultants, a wide range of specialties was represented. Table 1 shows the number and characteristics of those taking part.

\section{Findings from the presession-postsession questionnaire}

Primary and secondary care clinicians were broadly similar in expressing motivation for taking part, and the two most common themes for all clinicians was the desire to try and improve professional life at the interface for the benefit of patient care, and also the desire simply to meet and develop relationships with interface colleagues. In terms of what they would hope to get out of attending the session, clinicians shared a need to increase understanding of the 'other side's' working and to begin formulating solutions for interface related problems.

Based on postsession questionnaire analysis, clinicians appreciated meeting one another and the shared discussion. The most common thought on what may have gone better was that the session was too short and that a smaller group may have been more effective. GPs and hospital consultants both expressed surprise that group discussions were largely cordial: 


\section{Accept invitation and agree to participate}

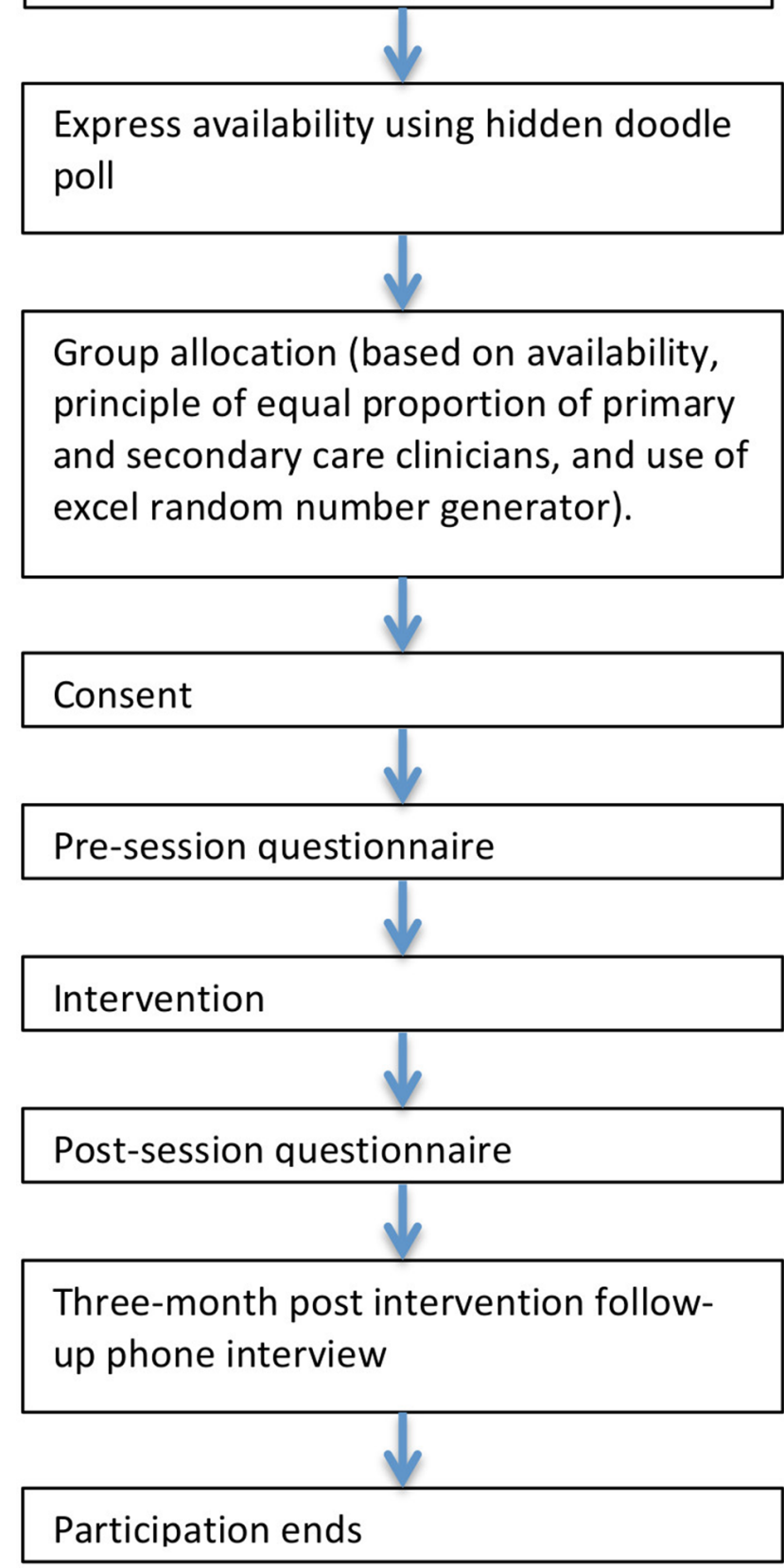

Figure 1 Summary of participant activity.

'I think I had suspected more irritation/animosity than was actually evident.' S20*

*Quote nomenclature; S20 refers to Secondary care based-participant number 20, P4 would refer to Primary care based-participant number 4 .

Largely, the positive role of facilitators in this regard was appreciated, though not universally so:

'I think there could have been more space for challenge and more confrontation and more difficult conversations [...] I think it pussyfooted around a bit and therefore some of the real big issues, the elephants in the room weren't allowed to come to the surface.' P1

\section{Findings from interview at 3 months postintervention}

Table 2 shows a summary of themes from analysis of participant response at interview 3 months postintervention.

\section{Understanding}

As a result of having taken part in the intervention, participants gained new knowledge of one another and the wider interface (connected to systems and processes; either linked to their own side of the interface or the other).

Clinicians expressed wonder at the level of ignorance of their interface colleagues, with some expressing surprise that colleagues on the other side of the interface faced similar problems, being 'as frustrated as we are':

'I think I was surprised at the how little the secondary care physicians have an understanding of the issues that were going on in primary care.' P25

Fresh insight into the problems that interface colleagues face led to a greater appreciation of one another on a personal level expressed in terms of compassion, sympathy and empathy:

'I think I it genuinely has helped me have less of an 'us and them' attitude if you know what I mean?' P4

This conciliatory tone is evidenced further with a GP and specialist, who prior to participation had experienced tension around perceived workload transfer across the interface:

'a [specialist] was there and we'd had some difficult interactions with regards to the monitoring a new [specialist department] drug, but actually her being there face to face, she is a very personable person and hearing her, the difficulties that were arising from her point of view was pretty invaluable to me because it $[\ldots]$ made me change my views on the whole issue.' P4

While from a specialist:

'the other thing was blood testing by the GP. [...] we were aware that some [city] GPs were not too happy about monitoring a couple of very specific drugs for us but we didn't really understand why, [...] but having that conversation with the GPs during the interview it became clear that their phlebotomy service was being kind of eaten up by hospital stuff and that they weren't being able to get their own you know blood tests done [...] it was something that I hadn't appreciated.' P12

New knowledge for specialists was not limited to that relating to primary care, those within secondary care also learnt something about systems within other specialist 


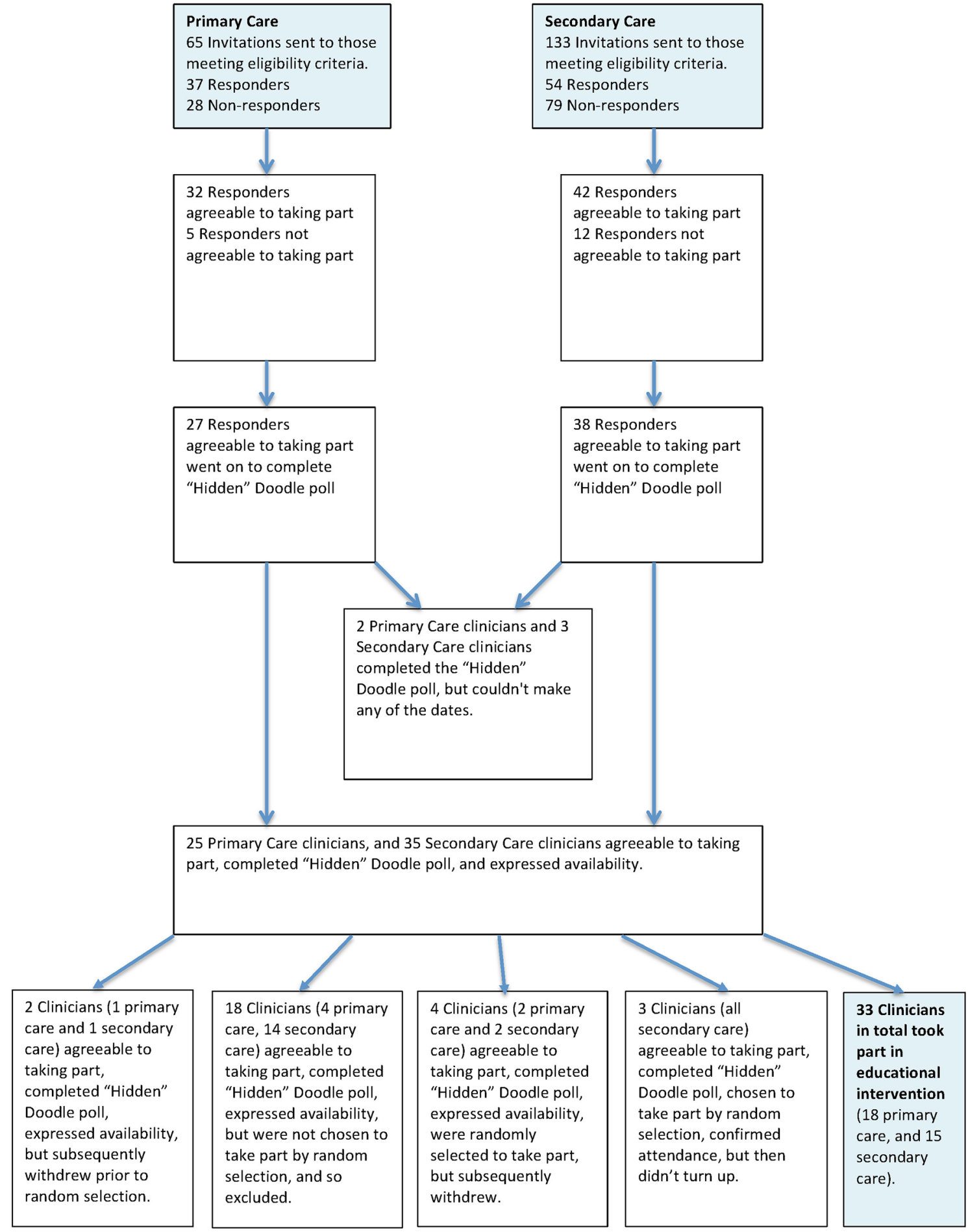

Figure 2 Invitation, response and involvement of study participants.

departments for example, how some departments might correspond directly with patients.

This sense of increased understanding as a result of taking part led to behavioural changes for some interface clinicians.

\section{Behavioural change}

Behavioural change describes modification in the way the clinicians conducted themselves, especially towards others.
Both GPs and specialists described feeling more able to contact the other and for example, 'pick up the phone' as a result of taking part in the intervention:

'I think it gave me a bit of greater confidence to actually approach some of the consultants to be honest.' P5

This change in perception of the other led one specialist to a different approach in an interface educational setting: 


\begin{tabular}{lllll}
\hline Table 1 & $\begin{array}{l}\text { Distribution and characteristics of participants } \\
\text { Primary care } \\
\text { participants total } \\
\text { (gender) }\end{array}$ & $\begin{array}{l}\text { Secondary care } \\
\text { participants total (gender) }\end{array}$ & $\begin{array}{l}\text { Secondary care specialties } \\
\text { represented }\end{array}$ & Notes \\
\hline 1 & $\begin{array}{l}\text { Six (four males, two } \\
\text { female) }\end{array}$ & $\begin{array}{l}\text { Six (three male, three } \\
\text { female) }\end{array}$ & $\begin{array}{l}\text { Orthopaedics, Psychiatry, } \\
\text { Acute Medicine, Obstetrics and } \\
\text { Gynaecology, Haematology, }\end{array}$ & All participants attended \\
& $\begin{array}{l}\text { Six (three male, three } \\
\text { female) }\end{array}$ & $\begin{array}{l}\text { Four (three male, one } \\
\text { female) }\end{array}$ & $\begin{array}{l}\text { Rheumatology, Vascular Surgery, } \\
\text { Paediatrics, Psychiatry }\end{array}$ & $\begin{array}{l}\text { Two secondary care } \\
\text { clinicians did not attend* }\end{array}$ \\
\hline 3 & female) & Five (three male, two female) & $\begin{array}{l}\text { Renal Medicine, Orthopaedics, } \\
\text { Cardiology, General Surgery, } \\
\text { Dermatology }\end{array}$ & $\begin{array}{l}\text { One secondary care } \\
\text { clinician did not attend* }\end{array}$ \\
\hline
\end{tabular}

Each group session lasted approximately $90 \mathrm{~min}$ and took place outwith routine working hours (commencing around 19:00 hours).

*Two clinicians had to cancel at short notice and subsequently contacted the research team to explain reasons for non-attendance, and one clinician failed to attend with no reason given.

'I think it possibly changed my assumptions about the interaction because I have been, I had been to a practice before that and I had been quite concerned that what I was going to get was a barrage of awful things about work, the ways in which we were failing in the [specialist] service [...] but I think from talking to some of the GPs on a different subject, and looking at specific cases, meant that I was able to say 'actually hang on, they are thinking in a positive light about us as well, they're not just thinking negatively,' so I was perhaps less defensive than I might have been or made less assumptions that it was all going to be negative content.' S20

Breaking down established perceptions of the other led to clinicians becoming more mindful of how actions may impact on interface colleagues' workload (eg, one specialist asking the clinic nurse to perform blood tests, where previously, they may have simple asked the GP to perform the investigation).

Specific behavioural change by one GP included the beginning of professional development work with one of the specialists present in their group.

Another area of change described was that in relation to communication.

Table 2 Summary of themes from interviews at 3 months postintervention

\begin{tabular}{ll}
\hline Theme & Subtheme \\
\hline $\begin{array}{l}\text { Understanding } \\
\text { Behavioural change }\end{array}$ & $\begin{array}{l}\text { Empowerment } \\
\text { Changing perceptions changing } \\
\text { behaviour }\end{array}$ \\
Communication & $\begin{array}{l}\text { Motivations } \\
\text { Mode } \\
\text { Method } \\
\text { Departmental level }\end{array}$ \\
\hline
\end{tabular}

\section{Communication}

Those taking part highlighted the need for 'better' communication. The nature of this communication between interface clinicians was reflected on by participants and led to changes in communication quality and method. This occurred at both an individual and a system level. A variety of motives existed when describing such changes, none more so than perceived necessity:

'we really do need to communicate better because I think the gulf between Primary and Secondary Care is increasing.' P38

Clinicians described changes in the nature of their communication, with some being more careful to truly listen to what their colleague was saying, or being more explicit in interface correspondence (either in terms of further investigation needed and in what timescale, or in unequivocally retaining clinical responsibility when sending an email). Modifying the manner of communication when tensions arose was also described;

'there's been a couple of times when I would have possibly written a letter back when a demand was made upon us and it did sort of halt me about the tone that I use.' P27

Changes in method of communication included reduction in the amount of 'headed paper letters' from primary care and greater use of email. The move from less formal 'headed paper letters (often as a means of obtaining specialist advice)' was as a direct result of experience (of problems with such letters) shared by specialists. In its place, some GPs moved to completion of formal electronic proformas (a software package enabling population of key clinical information described by specialists as being easier to process). On this specific topic however, changes made by one GP were clearly made in the context of greater uncertainty:

'as a result of your meeting now I'm confused [...] so I've now stopped doing that (sending less formal 
'headed paper letters') and I don't know whether that's to the detriment or not?' P18

These communication changes for some had led to direct influence on patient care:

'Yes we've got a lady whose got an unusual pelvic abscess and all sorts of problems going on and she has been admitted to [local hospital] a number of times with UTIs and all sorts of things [...]; she'd previously just been admitted [...] and I phoned him [Consultant] up and we avoided her going in to hospital, and he arranged an assessment on the ward, things were done and it avoided her going back in to hospital [to stay as an in-patient].' P17

Two individual specialists (from different departments) had perceived that setting up a generic departmental email system perhaps was not going to be helpful based on previous interaction with general practice colleagues. However, attending the session led to them reconsidering the establishment of a new system as evidenced by the following quote:

'Yes because the vibes that I had before were really strong just conversations with GPs on the phone sort of saying 'will this work?' but now that I realise it isn't the only view out there then perhaps we can set it up and see how it works.' S40

Other departmental level changes by specialists included the introduction of letters to GPs (communicating reasons for change in specialist prioritisation from that originally intended by the referring GP), and for one clinician, creation of specific time slot to facilitate easier access for GPs.

\section{DISCUSSION}

\section{Statement of the principal findings}

The majority of participants described a range of impacts at interview 3 months post intervention. These included fresh insights (in relation to those individuals and processes on the same, and other side, of the interface), adoption of new behaviours (eg, being more empowered to directly contact a colleague, taking steps to reduce the other's workload and changes in professional approach) and changes in terms of communication (including a desire to communicate more effectively and use of different methods).

\section{Strengths and weaknesses of the study}

Older clinicians who may have worked a long time in the area and (and presumably have already established working interface relationships or remember previous joint learning events) may have been influenced to participate by this opportunity to 'chat' with known colleagues. ${ }^{2}$ However, the use of the hidden Doodle poll helped prevent clinicians choosing into available session dates based on which participants they would wish to engage with, or conversely avoid. It is also of note that there did not appear to be any difference in impact when comparing younger versus older clinicians, that is, it would seem likely the educational intervention itself was influencing behaviour rather than simply the opportunity for older clinicians to 'catch-up.' Data on age of participants/non-participants were not collected, and given insufficient numbers of participants involved (for statistical power), it is difficult to draw firm conclusions on such differences across an age range.

No data were collected on those clinicians who chose not to respond to study invitations, or who initially agreed to take part and then withdrew. Therefore, it is not known whether potential differences between participants and non-participants were important. Having a balance of co-facilitators (one from each of primary and secondary care) was an asset, helping to minimise any sense of bias in terms of group dynamics for participants. Compared with 'standard' educational small groups (where relationships are built over time), these one-off sessions consisted of people who may have met for the first time. This may have hindered willingness to be 'open'. However, the module content encouraged group working since case scenario topics were relevant to the participants, that is, the PBSGL module cases scenarios were developed by those in the 'swampy lowlands (clinicians working at the interface)', for use by those in the 'swampy lowland'. ${ }^{6} 14$ RS is a GP in the area where the study took place, which may have influenced participant responses (both in terms of recruitment and what people actually said). ${ }^{15}$ Nevertheless, although RS may have been known as a GP, participants from both sides of the interface may not have had a personal or indeed professional knowledge of RS.

\section{Strengths and weaknesses in relation to other studies, discussing important differences in results}

Previous research has highlighted tribal perspectives, with specialists feeling 'they had little to learn from GPs'. ${ }^{16}$ More recent study suggests changing perspectives, with specialists preferring a less didactic (and perhaps historical) approach, towards a more shared methodology. ${ }^{2}$ Our work is potentially helpful for the health service, in demonstrating how educational interventions can be used across traditional silos, both to increase understanding and modify behaviour. In the context of improving referral processes at the interface, Blank et al recognised the necessity of a "whole-systems approach' rather than a pure focus on primary care. ${ }^{17}$ Abkari et al found that the likely success of local dissemination and implementation strategies (in relation to referral processes between primary and secondary care) appear to be improved if local secondary care providers are involved in educational activities. ${ }^{18}$ Our interface-focused intervention sought to acknowledge this concern by involving clinicians from both sides.

Self-reported changes are a commonly used reporting tool and have been described elsewhere in relation to small group working. ${ }^{19}{ }^{20}$ While self-reported changes are of inherent value, quantitative evidence of sustained, meaningful change may have greater worth. Herbert et al 
reported on a randomised control trial of PBSGL modules and/ or individual prescribing portraits on treating hypertension in primary care, which revealed changes in prescribing, sustained at 6 months in the group that used learning modules. ${ }^{21}$ We interviewed participants 3 months postintervention in order to determine any self-reported, on-going change in clinical behaviour. Participants portrayed greater use of email at the interface at 3 months postintervention. We know that email at the interface can play an important role should a GP require a 'quick answer' from a specialist in relation to patient care. ${ }^{5}$ Indeed, two individual specialists from distinct hospital departments were giving serious consideration to the set-up of generic specialist email (a system whereby a hospital department sets up a generic email address, creating a single point of contact, to help ensure clarity over focus of contact and often with some guarantee of timeliness of response). Prereferral e-consultation at the interface has been found to moderate referral effectively and ensure referrals were appropriate. ${ }^{17}$ There is also some evidence that generic specialist email may improve access to specialist advice for GPs, with benefit for patients. ${ }^{22}$

Direct communication with patients (ie, specialists writing directly to patients or 'copying in' to communication with the GP) increased as a result of being involved with the intervention. Elsewhere, involvement of patients in clinical communication was appreciated by them and is considered a useful method of information giving. ${ }^{23} 24$

Participants described a lower threshold for 'picking up the phone'. Research elsewhere involving primary care clinicians using telephone to access specialist advice about HIV care increased confidence among GPs and created less need to refer patients to specialists. ${ }^{25}$ This may be applicable in other medical conditions.

The desire for more specific communication across the interface, highlighted by participants in our study, has been highlighted as an area for improvement elsewhere. ${ }^{26}$

\section{Meaning of the study: possible explanations and implications for clinicians and policy-makers}

Clinicians appreciated what seemed for them to be a long forgotten and unique forum to engage with interface colleagues on a level playing field. The value of the intervention may have been its role in simply bringing two tribes together to learn from, with and about each other to improve collaboration and the quality of care. ${ }^{27}$ Notably, intratribal learning also seemed to take place. Policy-makers may consider how best to align primary and secondary care educational provision, in order to facilitate interface learning and development. Participants described sustained change at 3 months postintervention: participants' 'commitment to change' statements in a peer group have been demonstrated elsewhere to be of importance. ${ }^{28}$ It is of interest that the content of the case scenarios influenced specific aspects of clinical process (eg, the intervention included an email focused case, which led to email linked impact). Healthcare leaders may in future consider which areas of service delivery need change and work 'backwards' from there in creating a relevant small-group educational intervention, that is, the intervention content could address specific service needs.

\section{Unanswered questions and future research}

Coleman et al in their landmark study on medical innovation found some clinicians (those integrated in the community of their colleagues and/or with a predilection for innovation) more willing to adopt new ideas and behaviours early in a process. ${ }^{29}$ It is possible that those choosing to participate in the present study were similarly predisposed. In running a future study, there may be value in exploring to a greater depth the differences in characteristics between those choosing to participate or not, and how this influences willingness to change. Future research focused on exploring the reasons for non-response to study invite or those declining participation may also help in the design and planning of subsequent educational interventions (with the aim of addressing barriers and improving participation).

The intervention itself was pilot-tested prior to use in the present investigation. ${ }^{6}$ In preparing for an exploratory randomised control trial, it will be necessary to use participant experience gathered from the current study to optimise the intervention. Examples might include running the intervention over a session of longer duration in direct response to participant feedback from postsession questionnaire/interview.

Areas of impact described by participants provide a focus in terms of generating measurable outcomes for an exploratory randomised controlled trial. In relation to greater use of email at the interface, direct measurement of numbers of clinical email communication preintervention and postintervention could be ascertained. Whether intervention leads to development of departmental level system improvement would be readily identifiable. Asking clinicians to quantify level of direct telephone communication between colleagues may be reported. Analysis of correspondence across the interface, measuring mode of specific request and response, can be explored. There may also be of value in assessing patient experience in intervention and control groups: in terms of patient satisfaction, rates of referral to secondary care, referral rejection rates, time to secondary care assessment or from in-depth data obtained through qualitative interviews.

In conclusion, the present study has usefully explored the impact on clinicians of an educational intervention aiming to improve the primary/secondary care interface and has highlighted influences on patient care. The study has identified potential outcome measures for a future randomised controlled trial. Addressing key areas identified in the study may help to improve interface relationships and benefit patient care.

Correction notice This paper has been amended since it was published Online First. Owing to a scripting error, some of the publisher names in the references were replaced with 'BMJ Publishing Group'. This only affected the full text version, 
not the PDF. We have since corrected these errors and the correct publishers have been inserted into the references.

Twitter@SampsonRod

Acknowledgements The authors thank group facilitators Mr Angus Cain (Consultant Ear, Nose \& Throat), Dr Sian Jones (General Practice Principal), Dr Jerry 0'Rourke (General Practice Principal), Professor Ken Walker (Consultant Colorectal Surgeon), all based in NHS Highland. They also thank Gillian Heron, Cairn Medical Practice for transcription services.

Contributors RS designed the study, undertook the investigation, carried out the analysis and interpretation and wrote the manuscript. RMcV and PW participated in the design of the review, analysis and interpretation of findings and critical review of the manuscript. All authors had full access to all of the data (including tables) in the study and can take responsibility for the integrity of the data and the accuracy of the data analysis. RS is the guarantor.

Funding This work was supported by NHS Highland Research \& Development Committee [ref HIGHLAND 976]. Publication costs supported by NHS Education for Scotland, Centre for Rural Health (Aberdeen University, Inverness), and NHS Highland Research \& Development Committee. The Chief Investigator (Dr Rod Sampson) received no personal payment for the study. No drug company was involved in this research.

Ethics approval University of Aberdeen Ethics Review Board.

Provenance and peer review Not commissioned; externally peer reviewed.

Data sharing statement The data that support the findings of this study are available from the corresponding author upon reasonable request.

Open Access This is an Open Access article distributed in accordance with the Creative Commons Attribution Non Commercial (CC BY-NC 4.0) license, which permits others to distribute, remix, adapt, build upon this work non-commercially, and license their derivative works on different terms, provided the original work is properly cited and the use is non-commercial. See: http://creativecommons.org/ licenses/by-nc/4.0/

(C) Article author(s) (or their employer(s) unless otherwise stated in the text of the article) 2017. All rights reserved. No commercial use is permitted unless otherwise expressly granted.

\section{REFERENCES}

1. Van Saltman RB, Rico A, Boerma W, eds. Primary care in the driver's seat? Organisational reform in European primary care. Open University Press, 2006.

2. Sampson R, Barbour R, Wilson P. The relationship between GPs and hospital consultants and the implications for patient care: a qualitative study. BMC Fam Pract 2016;17:45.

3. Reeves S, Perrier L, Goldman J, et al. Interprofessional education: effects on professional practice and healthcare outcomes (update). Cochrane Database Syst Rev 2013:CD002213.

4. Sampson R, Cooper J, Barbour R, et al. Patients' perspectives on the medical primary-secondary care interface: systematic review and synthesis of qualitative research. BMJ Open 2015;5:e008708.

5. Sampson R, Barbour R, Wilson P. Email communication at the medical primary-secondary care interface: a qualitative exploration. Br J Gen Pract 2016;66:e467-e473.

6. Sampson R, MacVicar R, Wilson P. Development of an interfacefocused educational complex intervention. Educ Prim Care 2017:1-9.

7. Schon D. The Reflective Practitioner New York: basic books, 1983.
8. Craig P, Dieppe P, Macintyre S, et al. Developing and evaluating complex interventions: the New Medical Research Council guidance. BMJ 2008;337:a1655-983.

9. Greenhalgh T, Fahy N. Research impact in the community-based health sciences: an analysis of 162 case studies from the 2014 UK Research Excellence Framework. BMC Med 2015;13:232.

10. Campbell NC, Murray E, Darbyshire J, et al. Designing and evaluating complex interventions to improve health care. BMJ 2007;334:455-9.

11. Carline JD. Funding medical education research: opportunities and issues. Acad Med 2004;79:918-24.

12. Highland NHS. 'About NHS Highland. http://www.nhshighland.scot. nhs.uk/AboutUs/Pages/AboutUs.aspx (accessed 22.1.2015).

13. Glaser B, Strauss A. The discovery of grounded theory: strategies for qualitative research. Chicago: Aldine, 1967.

14. Marshall MN. Bridging the ivory towers and the swampy lowlands; increasing the impact of health services research on quality improvement. Int J Qual Health Care 2014;26:1-5.

15. McCarney R, Warner J, lliffe S, et al. The Hawthorne effect: a randomised, controlled trial. BMC Med Res Methodol 2007;7:30.

16. Marshall MN, Phillips DR. A qualitative study of the professional relationship between Family Physicians and Hospital Specialists. The Professional Geographer 1999;51:274-82.

17. Blank L, Baxter S, Woods HB, et al. What is the evidence on interventions to manage referral from primary to secondary nonemergency care? A systematic review and logic model synthesis. NHS, Health Services and Delivery Research, 2015; 3.

18. Akbari A, Mayhew A, Al-Alawi MA, et al. Interventions to improve outpatient referrals from primary care to secondary care. Cochrane Database of Systematic Reviews 2005. Issue 3. Art. No.: CD005471.

19. Macvicar R, Cunningham D, Cassidy J, et al. Applying evidence in practice through small group learning: a scottish pilot of a canadian programme. Education for Primary Care 2006;17:465-72.

20. Kelly DR, Cunningham DE, McCalister $P$, et al. Applying evidence in practice through small-group learning: a qualitative exploration of success. Qual Prim Care 2007;15:93-8.

21. Herbert CP, Wright JM, Maclure M, et al. Better Prescribing Project: a randomized controlled trial of the impact of case-based educational modules and personal prescribing feedback on prescribing for hypertension in primary care. Fam Pract 2004;21:575-81.

22. Gorman CL, Reynolds P, 2012. Conference: british Society for Rheumatology and British Health Professionals in Rheumatology annual meeting 2012, Rheumatology 2012. Glasgow United Kingdom. Rheumatology Email Advice and Liaison: A New Service. Rheumatology (United Kingdom), Conference Publication: (var. pagings). 51 (pp iii168), 2012. Date of Publication: May 2012; Conference Start: 20120501. Conference End: 20120503. [Journal: Conference Abstract]

23. Krishna Y, Damato BE. Patient attitudes to receiving copies of outpatient clinic letters from the ocular oncologist to the referring ophthalmologist and GP. Eye 2005;19:1200-4.

24. Plener I, Hayward A, Saibil F. E-mail communication in the management of gastroenterology patients: a review. Can J Gastroenterol Hepatol 2014;28:161-5.

25. Waldura JF, Neff S, Dehlendorf C, et al. Teleconsultation improves primary care clinicians' confidence about caring for HIV. J Gen Intern Med 2013;28:793-800.

26. Jacobs LG, Pringle MA. Referral letters and replies from orthopaedic departments: opportunities missed. BMJ 1990;301:470-3.

27. Thistlethwaite J. Interprofessional education: a review of context, learning and the research agenda. Med Educ 2012;46:58-70.

28. Wakefield JG. Commitment to change: exploring its role in changing physician behavior through continuing education. J Contin Educ Health Prof 2004;24:197-204.

29. Coleman JS, Katz E, Menzel H. Medical innovation: a diffusion study. Second Edition. Indianapolis: Bobbs-Merrill, 1966. (Published online 15 oct 2004). 